\title{
Activation of Toll-like receptor 7 inhibits the proliferation and migration, and induces the apoptosis of pancreatic cancer cells
}

\author{
BING-BING ZOU ${ }^{1 *}$, FANG WANG ${ }^{2 *}$, LEI LI ${ }^{2}$, FENG-WEI CHENG ${ }^{2}$, RUI JIN ${ }^{2}$, \\ $\mathrm{XIN} \mathrm{LUO}^{2}$, LI-XIN ZHU ${ }^{1}$, XIAOPING GENG ${ }^{1}$ and SHENG-QUAN ZHANG ${ }^{2}$ \\ ${ }^{1}$ Department of General Surgery, The First Affiliated Hospital of Anhui Medical University, Hefei, Anhui 230022; \\ ${ }^{2}$ Department of Biochemistry and Molecular Biology, Anhui Medical University, Hefei, Anhui 230032, P.R. China
}

Received August 29, 2014; Accepted May 13, 2015

DOI: $10.3892 / \mathrm{mmr} .2015 .4130$

\begin{abstract}
Pancreatic cancer is one of the most malignant types of tumor and has a poor prognosis. Toll-like receptor 7 (TLR7) has been found to be present and have different roles in different types of cancer cells. In the present study, the roles of TLR7 in BxPC-3 cells, a human pancreatic adenocarcinoma cell line, were investigated. The cells were treated with gardiquimod, an agonist of TLR7, following which the properties of the cells, including proliferation, migration, cell cycle and apoptosis, were analyzed. It was revealed that activation of TLR7 by gardiquimod inhibited cell proliferation and migration, and induced apoptosis of the cells. In addition, gardiquimod downregulated the expression levels of cyclin B1, cyclin E and B-cell lymphoma 2, while upregulating the expression of B-cell-associated $\mathrm{X}$ protein. These results suggested that the activation of TLR7 suppresses the progression of pancreatic cancer.
\end{abstract}

\section{Introduction}

Pancreatic cancer is one of the most life threatening and aggressive types of malignancy and has a global annual incidence rate of $\sim 8 / 100,000$ individuals (1). Due to recurrence, the 5-year survival rate is $\sim 3-5 \%(2,3)$. According to its histogenetic origin, pancreatic cancer can be classified into several types (4), and adenocarcinoma is the most common histological type (5).

Correspondence to: Professor Xiaoping Geng, Department of General Surgery, The First Affiliated Hospital of Anhui Medical University, 69 Meishan Road, Hefei, Anhui 230022, P.R. China

E-mail: xp_geng@163.net

Professor Sheng-Quan Zhang, Department of Biochemistry and Molecular Biology, Anhui Medical University, 81 Meishan Road, Hefei, Anhui 230032, P.R. China

E-mail:sqz36@yahoo.com

*Contributed equally

Key words: Toll-like receptor 7, gardiquimod, BxPC-3, proliferation, migration, apoptosis
Generally, genetic and environmental factors are involved in the development of pancreatic cancer $(6,7)$.

Numerous studies have focused on the molecular mechanisms of pancreatic cancer. Genetic alterations in several genes, including KRAS, TP53, p16/CDKN2A, SMAD4, BRCA2, STK11, PRSS1 and BRAF30 have been demonstrated to be involved in the development of pancreatic cancer (8-12). Several pathways, including the Raf/extracellular signal-regulated kinase pathway, the phosphoinositide 3-kinase pathway and the Ral guanine nucleotide dissociation stimulator pathway have also been identified to contribute to the initiation and progression of pancreatic cancer $(13,14)$. Furthermore, the above-mentioned genes and pathways are involved in the proliferation, invasion, metastasis and apoptosis of pancreatic cancer (15).

Toll-like receptors (TLRs) have been demonstrated to be involved in the pathogenesis of the pancreatic cancer $(16,17)$. Ochi et al (18) reported a novel role of TLR7 in the development and progression of pancreatic cancer through interference with cell cycle regulation and activation of multiple cell signaling pathways.

TLR7 is one of the pattern recognition receptors, which has been identified as a primary detector of bacterial and viral components (19). TLR7 can trigger a series of signaling pathways by binding to single-stranded RNA or small molecular chemicals, including imiquimod and its derivatives (20). The effect of TLR7 agonists on cancer cells remain contradictory $(21,22)$. In renal cells and bladder cancer cells, TLR7 agonists exhibit anti-proliferative and apoptosis-inducing effects by suppressing the expression of c-Myc and directly affecting cell growth and tumorigenesis $(23,24)$. By contrast, activation of TLR7 has been reported to promote the survival, proliferation and invasiveness of tumor cells, including B-cell chronic lymphocytic leukemia cells (25-27). Thus, the effects of TLR agonists on tumor cells require further investigation (28).

In the present study, the effects of the TLR7 agonist, gardiquimod, on the proliferation, the migration and the apoptosis of the BxPC-3 pancreatic cancer cell line were investigated.

\section{Materials and methods}

Reagents. The BxPC-3 human pancreatic cancer cell line cells were purchased from the Shanghai Cell Bank of Chinese Academy of Sciences (Shanghai, China). 
Gardiquimod was obtained from InvivoGen (San Diego, CA, USA). 3-(4,5-dimethylthiazol-2-yl)-5-(3-carboxymethoxy-phenyl)-2-(4-sulfophenyl)-2H-tetrazolium, inner salt (MTS) was obtained from Promega Corporation (Madison, WI, USA). Antibodies against $\beta$-actin (cat. no. sc-8432; mouse monoclonal IgG1), cyclin E (cat. no. sc-247; mouse monoclonal IgG2b), cyclin B1 (cat. no. sc-594; rabbit polyclonal $\mathrm{IgG}$ ), B-cell lymphoma (Bcl)-2 (cat. no. sc-7382; mouse monoclonal IgG1) and B-cell-associated X protein (Bax; cat. no. sc-493, rabbit polyclonal $\mathrm{IgG}$ ) were purchased from Santa Cruz Biotechnology, Inc. (Santa Cruz, CA, USA). Fluorescein isothiocyanate (FITC)-Annexin V and propidium iodide (PI) were obtained from BioSharp (Hefei, China). Primers (Table I) were purchased from Sangon Biotech Co. Ltd. (Shanghai, China). Trypsin, Triton X-100, RNase A, radioimmunoprecipitation (RIPA) assay buffer, phenylmethylsulfonyl fluoride (PMSF), bicinchoninic acid (BCA) assay kit and SDS-polyacrylamide gel electrophoresis (PAGE) gels were obtained from Sigma-Aldrich (St. Louis, MO, USA) and Tris-buffered saline with Tween-20 (TBST) was purchased from Sunshine Biotechnology Co., Ltd. (Nanjing, China). Fetal bovine serum (FBS), streptomycin and penicillin were obtained from Invitrogen Life Technologies (Shanghai, China).

Peripheral blood monouclear cell (PBMC) preparation. EDTA anticoagulated venous blood samples $(2 \mathrm{ml})$ were collected from healthy volunteers and PBMCs were isolated using lymphocyte separation medium (Tianjin Haoyang Biological Manufacture Co., Ltd., Tianjin, China). The expression of TLR7 in PBMCs was analyzed and served as a positive control. Written informed consent was obtained from the volunteers.

Cell culture. The BxPC-3 cells were cultured for 2 days in RPMI-1640 medium supplemented with 10\% FBS, $100 \mathrm{U} / \mathrm{ml}$ streptomycin and $100 \mathrm{U} / \mathrm{ml}$ penicillin at $37^{\circ} \mathrm{C}$ in a $5 \% \mathrm{CO}_{2}$ atmosphere. Upon reaching $70 \%$ confluence, the cells were passaged for use in the following experiments.

Reverse transcription-quantitative polymerase chain reaction $(R T-q P C R)$. BxPC-3 cells were seeded $\left(3 \times 10^{3}\right.$ cells/well) in 24-well plates and cultured in FBS-free media for 3 days. Total cellular RNA was extracted from the cells using TRIzol (Invitrogen Life Technologies, Carlsbad, CA, USA). RT-qPCR analysis of TLR7 and GAPDH were performed, as previously described (29). Briefly, samples were amplified in an Applied Biosystem 7500 Real-Time PCR System (Applied Biosystems Life Technologies, Foster City, CA, USA) for 40 cycles with the following conditions: Denaturation at $95^{\circ} \mathrm{C}$ for $15 \mathrm{sec}$, and annealing and extension at $60^{\circ} \mathrm{C}$ for $40 \mathrm{sec}$. The primer sequences used are presented in Table $\mathrm{I}$ and the relative expression of TLR7 was calculated using $2^{-\Delta \Delta C t}$.

MTS assay. The BxPC- 3 cells were seeded ( $3 \times 10^{3}$ cells/well) in 96-well plates and cultured in FBS-free RPMI-1640 for 1 day. The cells were continually cultured at $37^{\circ} \mathrm{C}$ in a $5 \%$ $\mathrm{CO}_{2}$ atmosphere and treated with different concentrations $(0,1.5,3$ and $5 \mu \mathrm{g} / \mathrm{ml})$ of gardiquimod for various time-periods $(0,12$ and $30 \mathrm{~min}, 1,3,6,12,24$ and $48 \mathrm{~h})$, following which $20 \mu 1$ MTS reagent was added. The cells were incubated
Table I. Primers used for reverse transcription-quantitative polymerase chain reaction analysis.

Gene Primer sequence

GAPDH Forward 5'-AGATCATCAGCAATGCCTCCTG-3' Reverse 5'-ATGGCATGGACTGTGGTCATG-3'

TLR7 Forward 5'-TAGGATCACTCCATGCCATCAA-3' Reverse 5'-CAGTGTCCACATTGGAAACACC-3'

TLR7, Toll-like receptor 7 .

for $2 \mathrm{~h}$ and absorbance was measured at $490 \mathrm{~nm}$ using a Spectrophotometer Multiskan GO (Thermo Fisher, Vantaa, Finland). The experiment was repeated a minimum of three times.

Flow cytometric analysis. The BxPC-3 cells were seeded in 12-well plates and treated with $3 \mu \mathrm{g} / \mathrm{ml}$ gardiquimod for different time-periods, between 1 and 5 days, in FBS-free RPMI-1640 at $37^{\circ} \mathrm{C}$ in a $5 \% \mathrm{CO}_{2}$ atmosphere. The cells were detached with trypsin and washed with phosphate-buffered saline (PBS), and were then BxPC-3 cells were suspended at a density of $3 \times 10^{5} / \mathrm{ml}$ and fixed in $70 \%$ alcohol for $30 \mathrm{~min}$. Subsequent to washing with PBS, $5 \mu 1$ Triton X-100, $3 \mu 1$ RNase A $(20 \mathrm{ug} / \mathrm{ml})$ and $1 \mu \mathrm{l}$ PI dye $(50 \mathrm{ug} / \mathrm{ml})$ were added to the cells. Following mixing at room temperature and maintenance in the dark for $30 \mathrm{~min}$, flow cytometric analysis was performed. For analysis of apoptosis in the cells, $5 \mu \mathrm{l}$ FITC-Annexin $\mathrm{V}$ and $5 \mu \mathrm{l} \mathrm{PI}$ were added to the resuspended cells at room temperature for $15 \mathrm{~min}$. Then the cells were detected by flow cytometry using a BD FACSVerse ${ }^{\mathrm{TM}}$ flow cytometer (BD Biosciences, San Jose, CA, USA). The cells in the lower left, lower right, upper right and upper left quadrant signified viable, early apoptotic, late apoptotic or necrotic cells, respectively. The experiment was repeated three times.

Western blot analysis. The BxPC-3 cells were cultured in FBS-free RPMI-1640 at $37^{\circ} \mathrm{C}$ in a $5 \% \mathrm{CO}_{2}$ atmosphere, following which gardiquimod ( $3 \mathrm{ug} / \mathrm{ml}$ ) was added and the cells were cultured for 0,12 and $30 \mathrm{~min}, 1,3,6,12,24$ and 48 h. Subsequent to washing with cold PBS, the cells were incubated in RIPA assay buffer containing $1 \mathrm{mM}$ PMSF fluoride for $30 \mathrm{~min}$ in an ice-water bath. Subsequent to protein quantification using a BCA method, $100 \mu \mathrm{g}$ proteins were loaded onto $12 \%$ SDS-PAGE gels and the separated proteins were transferred onto polyvinylidene difluoride membranes (EMD Millipore, Billerica, MA, USA). The membrane was blocked in TBST containing 5\% non-fat milk for $2 \mathrm{~h}$ at room temperature with agitation. The membranes were then incubated with primary antibodies against $\beta$-actin, cyclin B1, cyclin E, Bcl-2 and Bax (1:500) overnight at $4^{\circ} \mathrm{C}$. Subsequent to washing with TBST, the membrane was incubated in horseradish peroxidase-linked secondary antibody/TBST solution for $2 \mathrm{~h}$ at room temperature. The bound secondary antibodies were detected using chemiluminescence substrate (Pierce Biotechnology, Inc., Woburn, MA, USA) and were visualized by exposure to X-ray film. The band intensity was determined 


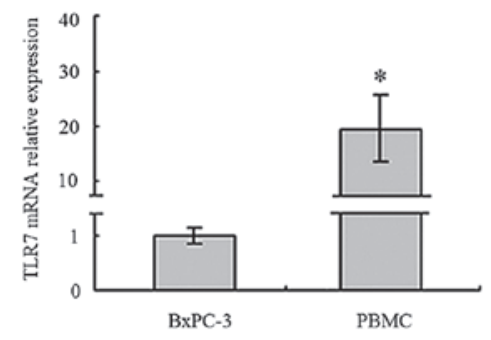

C

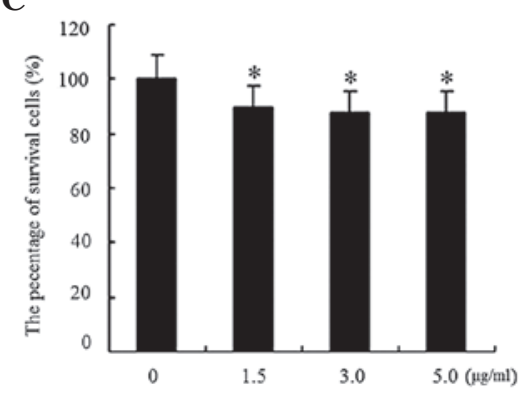

B

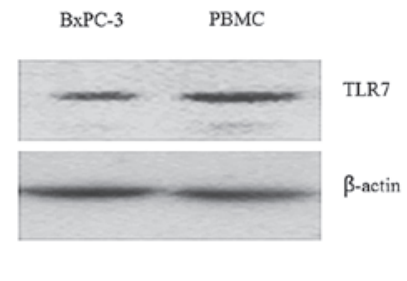

D

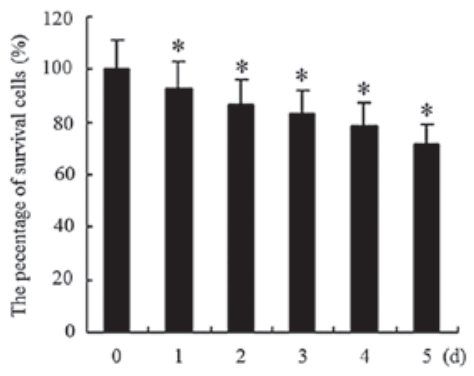

Figure 1. TLR7 is expressed in BxPC-3 cells, and gardiquimod inhibits the proliferation of BxPC-3 in a dose- and time-dependent manner. Total mRNA and protein were extracted from the cultured cells and used for (A) reverse transcription-quantitative polymerase chain reaction and (B) western blot analysis of the expression of TLR-7 in BxPC-3 cells at the mRNA level and protein levels, respectively. PBMCs were used as a positive control for the expression of TLR7. BxPC-3 cells were treated for 3 days with different concentrations of gardiquimod and (C) cell survival was determined. (D) Cell survival was determined following treatment with $3 \mu \mathrm{g} / \mathrm{ml}$ gardiquimod for different durations. Cell viability was determined using an MTS assay. The data are presented as the mean \pm standard deviation. The data expressed are representative of a minimum of three experiments. "P $<0.05$, vs. untreated control. TLR7, Toll-like receptor 7; PBMC, peripheral blood mononuclear cells.

using a Gel Image Analysis system and were normalized to $\beta$-actin.

Scratch/migration assay. The BxPC-3 cells were cultured in 24-well dishes $\left(5 \times 10^{4}\right.$ cells/well) for $24 \mathrm{~h}$ at $37^{\circ} \mathrm{C}$ in a $5 \%$ $\mathrm{CO}_{2}$ atmosphere. A $10-\mu 1$ pipette tip was used to scratch three perpendicular lines on the bottom of dishes. Following washing with PBS, gardiquimod $(3 \mu \mathrm{g} / \mathrm{ml})$ was added to the cells for different time periods (1-5 days) at $37^{\circ} \mathrm{C}$ in a $5 \%$ $\mathrm{CO}_{2}$ atmosphere. The distance that the cells migrated into the scratched region was quantified using the ocular micrometer of a Nikon Ecolipse TS100 microscope (Nikon Corporation, Tokyo, Japan; 10X objective lens, 1 unit $=10 \mathrm{~mm}$ ). The assessment was repeated three times.

Statistical analysis. All experiments were repeated a minimum of three times and the representative results are presented. The data are presented as means \pm standard deviation. Student's t-test, analysis of variance and the $\chi^{2}$ analysis were conducted using SPSS software, version 13.0 (SPSS, Inc., Chicago, IL, USA) and $\mathrm{P}<0.05$ was considered to indicate a statistically significant difference.

\section{Results}

TLR7 is expressed in BxPC-3 cells. In the present study, total RNA and protein were extracted from the BxPC-3 cells, following which RT-qPCR and western blot analysis were used to analyze the mRNA and protein expression levels of TLR, respectively. Peripheral blood mononuclear cells (PBMCs) were used as a positive control sample. Compared with the
PBMCs, the expression of TLR7 in the BxPC-3 cells was reduced at the mRNA (Fig. 1A) and protein (Fig. 1B) levels.

Gardiquimod inhibits the proliferation of BxPC-3 cells in a dose-and time-dependent manner. Treatment of gardiquimod inhibited the proliferation of the BxPC3 cells. The inhibition ratio was $10.41 \%$ at a low concentration $(1.5 \mu \mathrm{g} / \mathrm{ml})$ and $20.12 \%$ at a high concentration $(5 \mu \mathrm{g} / \mathrm{ml}$; P<0.05; Fig. $1 \mathrm{C})$. The time course analysis indicated that the inhibition ratio gradually increased between 7.01 and $28.55 \%$ between days 1 and 5 following the addition of $3 \mu \mathrm{g} / \mathrm{ml}$ gardiquimod $(\mathrm{P}<0.05$; Fig. 1D).

Analysis of the cell cycle analysis using flow cytometry demonstrated that the percentage of BxPC-3 cells treated with gardiquimod in the $\mathrm{G}_{1}$ phase gradually increased between 76.41 and $82.97 \%$ (Fig. 2). In addition, the percentage of cells in the $\mathrm{S}$ phase reduced between 19.13 and $10.09 \%$ as the duration of treatment increased (Fig. 2).

Gardiquimod induces the apoptosis of BxPC-3 cells. The effect of gardiquimod on the apoptosis of BxPC-3 cells was also examined (Fig. 3). The percentage of cells in the early apoptotic phase increased between $11.5 \%$ at day 1 and $19.32 \%$ at day 5. There was a statistically significant difference between the control group (Fig. 3A) and the groups treated with gardiquimod for $>3$ days $(\mathrm{P}<0.05$; Fig. 3D-F).

Gardiquimod reduces the expression levels of cyclin B1, cyclin $E$ and $B c l-2$, and increases the protein expression levels of Bax. Based on the results of the MTS and flow cytometry, gardiquimod was found to inhibit the proliferation 
A

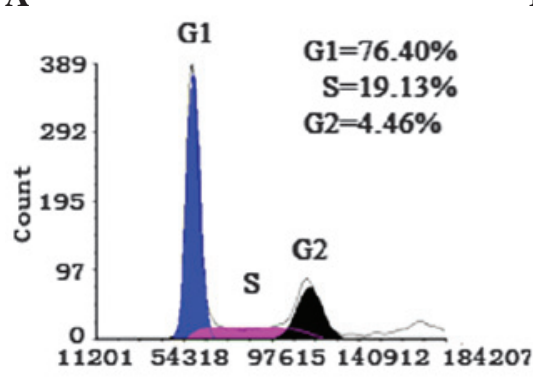

Propidium iodide-A

D

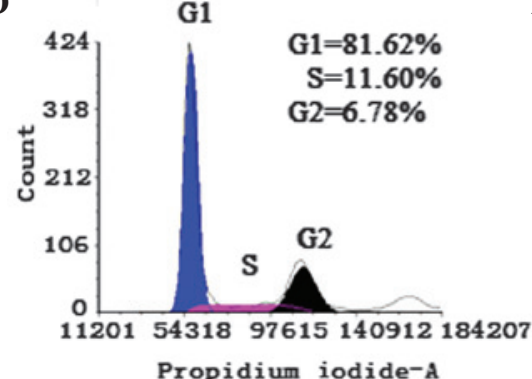

B

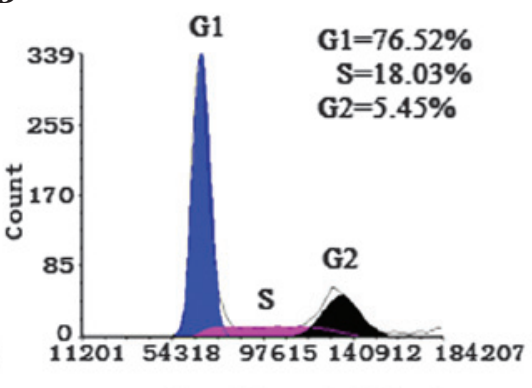

Propidium iodide-A

E

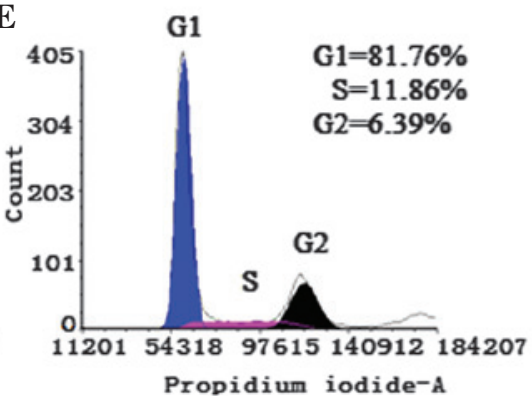

C

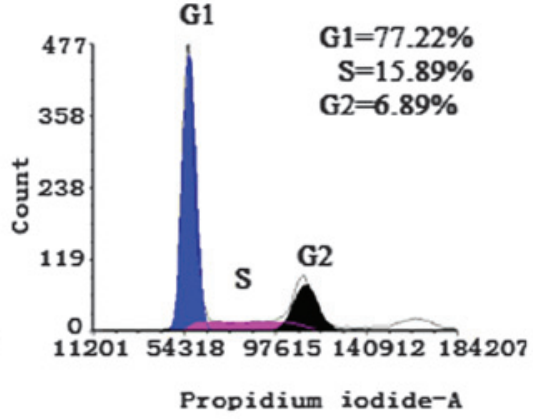

F

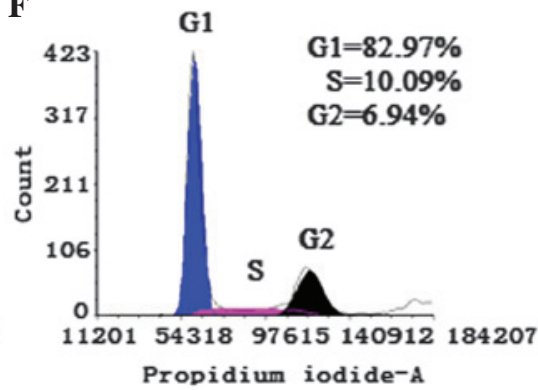

Figure 2. Gardiquimod inhibits cell proliferation at the $\mathrm{G}_{1}$ phase. The BxPC-3 cells were treated with gardiquimod (3 $\left.\mu \mathrm{g} / \mathrm{ml}\right)$ for different time-periods (0-5 days) and the cell cycle was detected using flow cytometry. (A) Control (untreated); (B) 1 day; (C) 2 days; (D) 3 days; (E) 4 days; and (F) 5 days $(\mathrm{P}<0.05$, vs. control). The results are from three independent experiments. The percentages of cells in each phase are presented.

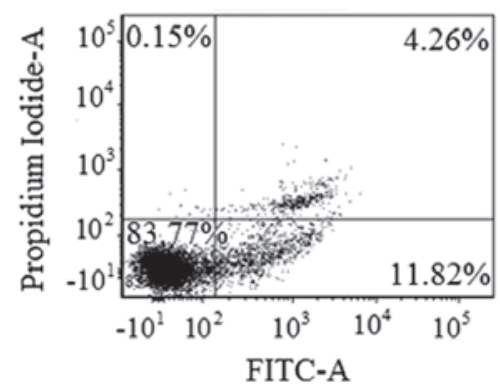

D

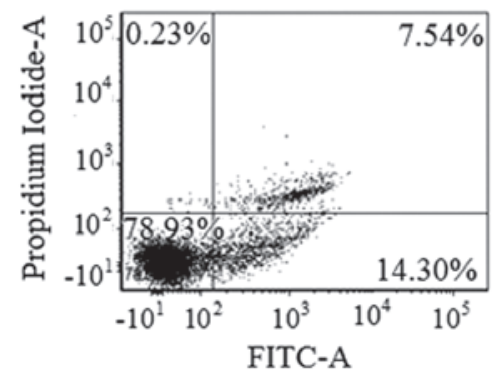

B

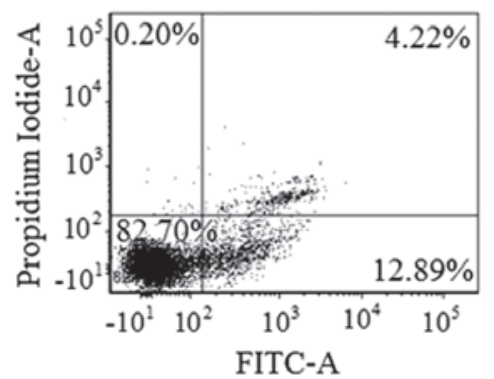

E

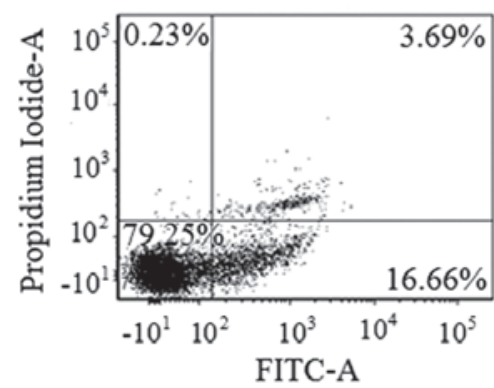

C

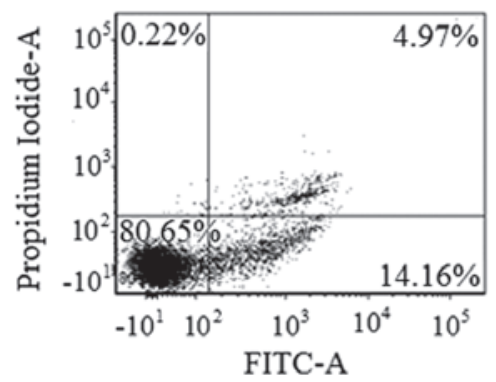

$\mathbf{F}$

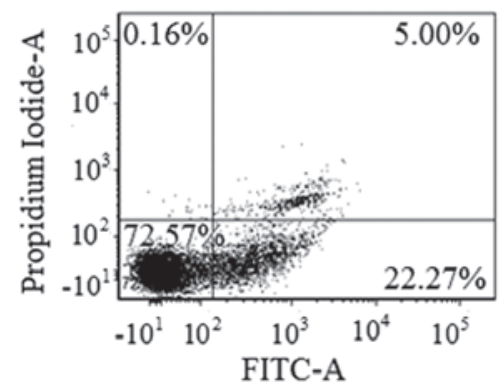

Figure 3. Gardiquimod induces apoptosis of BxPC-3 cells. The BxPC-3 cells were treated with gardiquimod (3 $\mu \mathrm{g} / \mathrm{ml})$ for different time-periods and the percentages of apoptotic cells were determined using flow cytometry. (A) Control (untreated); (B) 1 day; (C) 2 days; (D) 3 days; (E) 4 days; and (F) 5 days. $(\mathrm{P}<0.05$, vs. control). The cells in the lower left, lower right, upper right and upper left quadrant signify the viable, early apoptotic, late apoptotic or necrotic cells, respectively. The percentages in the quadrants of each panel indicate the ratio of the different cells. FITC, fluorescein isothiocyanate.

and induce the apoptosis of the $\mathrm{BxPC}-3$ cells. In order to investigate the underlying mechanism, western blot analysis was performed to analyze changes in the expression levels of cyclin B1, cyclin E, Bcl-2 and Bax in the BxPC-3 cells treated with gardiquimod. As shown in Fig. 4A, treatment with gardiquimod reduced the expression levels of cyclin B1, cyclin $\mathrm{E}$ and $\mathrm{Bcl}-2$ in the BxPC-3 cells and, following treatment for $12 \mathrm{~h}$, the expression levels of these three proteins markedly reduced. By contrast, gardiquimod induced the expression of Bax. 
A

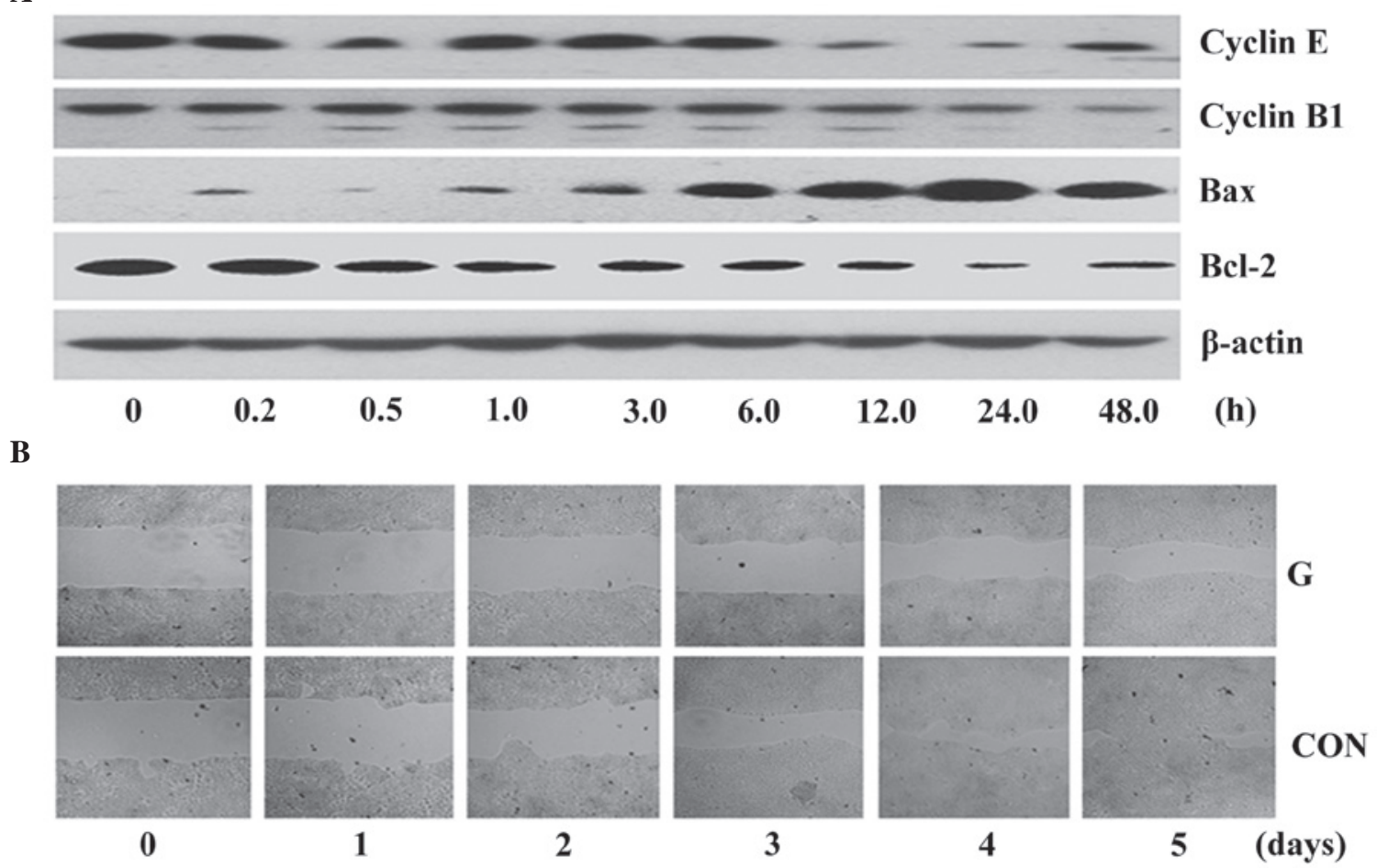

Figure 4. Gardiquimod reduces the expression levels of cyclin B1, cyclin E and Bcl-2, increases the expression of Bax at the protein level and inhibits the migration of BxPC-3. (A) BxPC-3 cells were treated with gardiquimod $(3 \mu \mathrm{g} / \mathrm{ml})$ for various time-periods and the expression levels of cyclin B1, cyclin E, Bcl-2 and Bax were determined using western blot analysis. The results represent one of three independent experiments. (B) BxPC-3 cells were treated with gardiquimod $(3 \mu \mathrm{g} / \mathrm{ml})$ for 1 day, following which the surface of the cell layer was scratched and continually cultured for 6 days, monitoring the scratched space daily under a microscope (magnification, x100). Bcl, B-cell lymphoma; Bax, B-cell-associated X protein; G, gariquimod-treated; Con, untreated.

Gardiquimod inhibits the migration of BxPC-3 cells. Cancer cells can migrate from their original sites and invade into adjacent normal tissues or into the blood or lymph vessels, and form additional neoplasms. In the present study, a scratch/migration assay was used to detect the effects of gardiquimod on the migration of BxPC-3 cells. In the control group, without gardiquimod treatment, the BxPC-3 cells occupied almost the entire scratched space at day 5 , however, in the groups treated with gardiquimod, $\sim 60 \%$ of the space present at day 0 remained unoccupied at day 5 (Fig. 4B).

\section{Discussion}

Pancreatic cancer is one of the five most common causes of cancer-associated mortality (30). In the present study, gardiquimod was used to treat BxPC-3 pancreatic cancer cells, and the results demonstrated that gardiquimod inhibited the proliferation and migration, and induced the apoptosis of the BxPC-3 cells. The effect of gardiquimod on the proliferation of the BxPC-3 cells may be involved in the regulation of the expression levels of cyclin B1, cyclin E, Bcl-2 and Bax.

Previous studies have demonstrated that TLR7 signaling pathways have different roles in different types of cancer. TLR7 agonists have been suggested to be antiproliferative and induce apoptosis in renal cancer cells and bladder cancer cells, including normal $\mathrm{T}$ cells $(23,24)$. By contrast, they can promote the survival, proliferation and migration of tumor cells, including B-cell chronic lymphocytic leukemia cells (25-27). Ochi et al (18) previously demonstrated that the TLR7 agonist, ssRNA40, stimulates the proliferation of pancreatic cancer cells, but had no effect on the pancreatic cells of wild mice (18). In addition, the activation of TLR7 was demonstrated to regulate the expression levels of a series of genes, including phosphatase and tensin homolog, p16, p21, p27, p53, Rb, c-Myc, transforming growth factor- $\beta$ and SHPTP1 (18). The results of the present study appear to be in contradiction with the observations of Ochi et al (18), however, the present study used BxPC-3 cells as a model, unlike the pancreatic cancer cells from $\mathrm{p} 48^{\mathrm{Cre}} ; \mathrm{Kras}^{\mathrm{G} 12 \mathrm{D}}$ mice, which were used as the model in the study by Ochi et al. The Kras gene was sequenced in the present study, and no $\mathrm{Kras}^{\mathrm{G} 12 \mathrm{D}}$ mutation was identified (data not shown). This suggested that cell lines with different genetic backgrounds may have entirely different responses to treatment with gardiquimod. These paradoxical results suggest that the TLR7 agonists have opposite effects, even in different cell lines from the same type of cancer. However, the molecular mechanism of this phenomena requires further investigation, which may assist in the development of novel therapeutic methods for cancer.

The expression of cyclin is a key element in the control of the cell cycle. In the present study, gardiquimod was observed to reduce the expression levels of cyclin B1 and cyclin E, which suggested that gardiquimod may exert its antiproliferative effects at the transition of the $\mathrm{G}_{1}-\mathrm{S}$ phase. It has been previously reported that gardiquimod exerts its antiproliferative activity in urothelial cell carcinoma via downregulating the expression of cyclin D2 (24, therefore, the antiproliferative mechanism of gardiquimod appears similar between BxPC-3 
cells and urothelial cell carcinoma (24). On analyzing apoptosis in the present study, gardiquimod was found to induce apoptosis; which was consistent with its effect on renal cells (31). It is well known that the apoptosis-associated proteins, Bcl-2 and Bax (32), are important in the process of apoptosis in cells $(33,34)$. In the present study, gardiquimod was observed to regulate the expression of these two genes. All these results suggested that gardiquimod may exert its antiproliferative activity and induce apoptosis on the BxPC-3 cells via the regulation of proliferation and the expression levels of apoptosis-associated genes. These results also provide insight into the pathogenesis of pancreatic cancer, potentially and may assist in the development of novel treatment strategies. However, there are several details, which remain to be fully elucidated, thus, the effects of TLR agonists on tumor cells require careful further investigation prior to their application in immunotherapy. The present study also assessed the effects of gardiquimod on the migration of the BxPC-3 cells and demonstrated that, following wounding, the cells treated with gardiquimod healed more slowly, compared with those in the control group. The molecular mechanism underlying this phenomenon remains to be elucidated and requires investigation in subsequent investigations.

In conclusion, the results of the present study suggested that gardiquimod inhibited the proliferation and migration, and induced the apoptosis of BxPC-3 pancreatic cancer cells, which may assist in elucidating the involvement of TLR7 in the development of pancreatic cancer.

\section{Acknowledgements}

This study was supported by grants from the General Program of the National Natural Science Foundation of China (grant. no. 81271748) and the Foundation for Doctors, Anhui Medical University (Hefei, China; grant no. 0108016101).

\section{References}

1. Raimondi S, Maisonneuve P and Lowenfels AB: Epidemiology of pancreatic cancer: An overview. Nat Rev Gastroenterol Hepatol 6: 699-708, 2009.

2. Steele CW, Jamieson NB, Evans TR, McKay CJ, Sansom OJ, Morton JP and Carter CR: Exploiting inflammation for therapeutic gain in pancreatic cancer. Br J Cancer 108: 997-1003, 2013

3. Jemal A, Siegel R, Ward E, Hao Y, Xu J and Thun MJ: Cancer statistics. CA Cancer J Clin 59: 225-249, 2009.

4. Cooper CL, O'Toole SA and Kench JG: Classification, morphology and molecular pathology of premalignant lesions of the pancreas. Pathology 45: 286-304, 2013.

5. Alexakis N, Halloran C, Raraty M, Ghaneh P, Sutton R and Neoptolemos JP: Current standards of surgery for pancreatic cancer. Br J Surg 91: 1410-1427, 2004.

6. Lin Y, Yagyu K, Egawa N, Ueno M, Mori M, Nakao H, Ishii H, Nakamura K, Wakai K, Hosono S, et al: An overview of genetic polymorphisms and pancreatic cancer risk in molecular epidemiologic studies. J Epidemiol 21: 2-12, 2011.

7. Nitsche C, Simon P, Weiss FU, Fluhr G, Weber E, Gärtner S, Behn CO, Kraft M, Ringel J, Aghdassi A, et al: Environmental risk factors for chronic pancreatitis and pancreatic cancer. Dig Dis 29: 235-242, 2011.

8. Iacobuzio-Donahue CA, Velculescu VE, Wolfgang CL and Hruban RH: The genetic basis of pancreas cancer development and progression: Insights from whole-exome and whole-genome sequencing. Clin Cancer Res 18: 4257-4265, 2012 .
9. Jones S, Zhang X, Parsons DW, Lin JC, Leary RJ, Angenendt P, Mankoo P, Carter H, Kamiyama H, Jimeno A, et al: Core signaling pathways in human pancreatic cancers revealed by global genomic analyses. Science 321: 1801-1806, 2008.

10. Petersen GM, de Andrade M, Goggins M, Hruban RH, Bondy M, Korczak JF, Gallinger S, Lynch HT, Syngal S, Rabe KG, et al: Pancreatic cancer genetic epidemiology consortium. Cancer Epidemiol Biomarkers Prev 15: 704-710, 2006.

11. Klein AP, Brune KA, Petersen GM, Hruban RH, Bondy M, Korczak JF, Gallinger S, Lynch HT, Syngal S, Rabe KG, et al: Prospective risk of pancreatic cancer in familial pancreatic cancer kindreds. Cancer Res 64: 2634-2638, 2004.

12. Shi C, Hruban RH and Klein AP: Familial pancreatic cancer. Arch Pathol Lab Med 133: 365-374, 2009.

13. Siveke JT, Einwächter H, Sipos B, Lubeseder-Martellato C, Klöppel G and Schmid RM: Concomitant pancreatic activation of Kras (G12D) and Tgfa results in cystic papillary neoplasms reminiscent of human IPMN. Cancer Cell 12: 266-279, 2007.

14. Ma J, Sawai H, Ochi N, Matsuo Y, Xu D, Yasuda A, Takahashi H, Wakasugi $\mathrm{T}$ and Takeyama H: PTEN regulates angiogenesis through PI3K/Akt/VEGF signaling pathway in human pancreatic cancer cells. Mol Cell Biochem 331: 161-171, 2009.

15. Mihaljevic AL, Michalski CW, Friess H and Kleeff J: Molecular mechanism of pancreatic cancer-understanding proliferation, invasion and metastasis. Langenbecks Arch Surg 395: 295-308, 2010.

16. Ikebe M,Kitaura Y,Nakamura M,Tanaka H, Yamasaki A,Nagai S, Wada J, Yanai K, Koga K, Sato N, et al: Lipopolysaccharide (LPS) increases the invasive Aability of pancreatic cancer cells through the TLR4/MyD88 signaling pathway. J Surg Oncol 100: 725-731, 2009.

17. Mai CW, Kang YB and Pichika MR: Should a Toll-like receptor 4 (TLR-4) agonist or antagonist be designed to treat cancer? TLR-4: its expression and effects in the ten most common cancers. Onco Targets Ther 6: 1573-1587, 2013.

18. Ochi A, Graffeo CS, Zambirinis CP, Zambirinis CP, Rehman A, Hackman M, Fallon N, Barilla RM, Henning JR, Jamal M, et al: Toll-like receptor 7 regulates pancreatic carcinogenesis in mice and humans. J Clin Invest 122: 4118-4129, 2012.

19. Olivier M: Host-pathogen interaction: Culprit within a culprit. Nature 471: 173-174, 2011

20. Zhu J, Lai K, Brownile R, Babiuk LA and Mutwiri GK: Porcine TLR8 and TLR7 are both activated by a selective TLR7 ligand, imiquimod. Mol Immunol 45: 3238-3243, 2008.

21. Shojaei H, Oberg HH, Juricke M, Marischen L, Kunz M, Mundhenke C, Gieseler F, Kabelitz D and Wesch D: Toll-like Receptors 3 and 7 Agonists Enhance Tumor Cell T Cells Lysis by Human. Cancer Res 69: 8710-8717, 2009.

22. Kutikhin AG: Association of polymorphisms in TLR genes and in genes of the Toll-like receptor signaling pathway with cancer risk. Hum Immunol 72: 1095-1116, 2011.

23. Schwartz MJ, Liu H, Hwang DH, Kawamoto H and Scherr DS: Antitumor effects of an imidazoquinoline in renal cell carcinoma. Urology 73: 1156-1162, 2009.

24. Liu H, Schwartz MJ, Hwang DH and Scherr DS: Tumour growth inhibition by an imidazoquinoline is associated with c-Myc down-regulation in urothelial cell carcinoma. BJU Int 101: 894-901, 2008

25. Funderburg N, Luciano AA, Jiang W, Rodriguez B, Sieg SF and Lederman MM: Toll-like receptor ligands induce human $\mathrm{T}$ cell activation and death, a model for HIV pathogenesis. PLoS One 3: e1915, 2008.

26. François S, El Benna J, Dang PM, Pedruzzi E, Gougerot-Pocidalo MA and Elbim C: Inhibition of neutrophil apoptosis by TLR agonists in whole blood: involvement of the phosphoinositide3-kinase/Akt and NF-kappaB signaling pathways, leading to increased levels of Mcl-1, A1 and phosphorylated Bad. J Immunol 174: 3633-3642, 2005.

27. Hammadi A, Billard C, Faussat AM and Kolb JP: Stimulation of iNOS expression and apoptosis resistance in B-cell chronic lymphocytic leukemia (B-CLL) cells through engagement of Toll-like receptor 7 (TLR-7) and NF-kappaB activation. Nitric Oxide 19: 138-145, 2008.

28. Zambirinis CP and Miller G: Signaling via MYD88 in the pancreatic tumor microenvironment. Oncoimmunology 2: e22567, 2013.

29. Li L, Cheng FW, Wang F, Jia B, Luo X and Zhang SQ: The activation of TLR7 regulates the expression of VEGF, TIMP1, MMP2, IL-6 and IL-15 in Hela cells. Mol Cell Biochem 389: 43-49, 2014. 
30. Bosetti C, Bertuccio P, Negri E, La Vecchia C, Zeegers MP and Boffetta P: Pancreatic cancer: overview of descriptive epidemiology. Mol Carcinog 51: 3-13, 2012.

31. Schwartz MJ, Liu H, Hwang DH, Kawamoto H and Scherr DS Antitumor effects of an imidazoquinoline in renal cell carcinoma. Urology 73: 1156-1162, 2009.

32. Sasi N, Hwang M, Jaboin J, Csiki I and Lu B: L Regulated cell death pathways: new twists in modulation of BCL2 family function. Mol Cancer Ther 8: 1421-1429, 2009.
33. Pietrantonio F, Biondani P, Ciurlia E, Fanetti G, Tessari A, Bertarelli G, Bossi I, Musella V,Melotti F, Di Bartolomeo M, et al: Role of BAX for outcome prediction in gastrontestinal malignancies. Med Oncol 30: 610, 2013.

34. Rubenstein M, Hollowell CM and Guinan P: Differentiated prostatic antigen expression in cells following treatment with bispecific antisense oligonucleotides directed against BCL-2 and EGFR. Med Oncol 29: 835-841, 2012. 